\title{
Aiming towards hepatitis C virus elimination in Greece
}

\section{George V. Papatheodoridisa, John Goulis ${ }^{\mathrm{b}}$, Vana Sypsac, Christos Lionis ${ }^{\mathrm{d}}$, Spilios Manolakopoulose, loannis Elefsiniotis', Olga Anagnostou' ${ }^{g}$, Christos Tsoulas' ${ }^{h}$, Angelos Hatzakisc, George N. Dalekosi}

Medical School of National and Kapodistrian University of Athens, Laiko General Hospital; Aristotle University of Thessaloniki Medical School; Medical School of National and Kapodistrian, University of Athens, Epidemiology \& Medical Statistics; School of Medicine, University of Crete, Heraklion, Crete; Medical School of National and Kapodistrian University of Athens, Hippokratio General Hospital of Athens; General and Oncology Hospital Agioi Anargyroi, Athens; Greek Organisation Against Drugs (OKANA), Athens; Gilead Sciences Hellas, Athens; University of Thessaly Medical School, Larissa, Greece

\begin{abstract}
There are estimated to be 74,000-134,000 patients living with chronic hepatitis C in Greece, but only $20-30 \%$ of them are aware of their disease status. In July 2017 , the Hellenic National Plan for Hepatitis $\mathrm{C}$ was announced in alignment with the World Health Organization goals for the eradication of hepatitis $\mathrm{C}$ virus (HCV) by the year 2030. This article discusses the epidemiology and current treatment of chronic hepatitis $\mathrm{C}$ in Greece. Additionally the authors propose actions on how to bring back to care diagnosed patients lost to follow up, optimize access to care for HCVinfected people who inject drugs, and increase HCV screening in the general population. The medical community in Greece can play a pivotal role in the implementation of the HCV National Plan and in the efforts to reach the goal of HCV elimination.
\end{abstract}

Keywords Hepatitis C, elimination, Greece, screening, linkage to care

Ann Gastroenterol 2019; 32 (3): 1-9

\section{Introduction}

The prevalence of hepatitis $\mathrm{C}$ virus (HCV) infection in Greece is estimated to be between $0.83 \%$ and $1.79 \%$ in the general population and $1.03-1.87 \%$ when the estimations take

${ }^{a}$ Department of Gastroenterology, Medical School of National and Kapodistrian University of Athens, Laiko General Hospital (George V. Papatheodoridis); $4^{\text {th }}$ Department of Internal Medicine, Aristotle University of Thessaloniki Medical School (John Goulis); ' Department of Hygiene, Medical School of National and Kapodistrian, University of Athens, Epidemiology and Medical Statistics, Athens (Vana Sypsa, Angelos Hatzakis); 'Clinic of Social and Family Medicine, School of Medicine, University of Crete, Heraklion-Crete (Christos Lionis); $2^{\text {nd }}$ Department of Internal Medicine, Medical School of National and Kapodistrian University of Athens, Hippokratio General Hospital of Athens (Spilios Manolakopoulos); ${ }^{\mathrm{f}}$ Academic Department of Internal MedicineHepatogastroenterology, "Agioi Anargyroi” General and Oncology Hospital, Athens (Ioannis Elefsiniotis); ${ }^{\mathrm{B}}$ Greek Organisation Against Drugs (OKANA), Athens (Olga Anagnostou); ${ }^{\text {} M e d i c a l ~ D e p a r t m e n t, ~ G i l e a d ~}$ Sciences Hellas, Athens (Christos Tsoulas); ${ }^{i}$ Department of Medicine and Research Laboratory of Internal Medicine, University of Thessaly Medical School, Larissa (George N. Dalekos), Greece

Correspondence to: Christos Tsoulas MD, MSc, Associate Medical Director, Liver Diseases, GILEAD SCIENCES HELLAS, Rizountos 2 and Thrakis Street, 16777 Athens, Greece, e-mail: christos.tsoulas@gilead.com

Received 21 March 2018; accepted 12 March 2019; published online 5 April 2019

DOI: https://doi.org/10.20524/aog.2019.0375 into account high-risk patient groups $[1,2]$. This means that between 74,000 and 134,000 adults in the general population have chronic hepatitis $\mathrm{C}$ (Table 1 ).

Based on current data, HCV infection in Greece seems to be underdiagnosed and undertreated. It is estimated that only $20-30 \%$ of HCV patients are aware of their disease and approximately $36-58 \%$ of the diagnosed patients have received treatment, most of them with interferon-based regimens [1,2]. Additionally, it is estimated that there are approximately 3700 new HCV infections per year [3,4], with the majority of new infections (7 of 10 in the years 1992-2004) occurring among people who inject drugs (PWID) [4-6].

Genotype (GT) 1 is the most prevalent one (45\%) followed by GT3 (33\%). The prevalence of the remaining GTs is $13 \%$ for GT4 and 7\% for GT2 $[7,8]$. GT3 is mainly related to intravenous (IV) drug use [9] and its incidence has been rising in relation to the other GTs during the last two decades $[7,10]$.

Greek authorities have expressed their willingness to eliminate HCV by year 2030, consistent with the World Health Organization (WHO) strategy of HCV elimination [11]. In this context, an HCV National Plan was announced in July 2017 by the Ministry of Health [4]. However, significant challenges remain for the implementation of the National Plan towards HCV elimination.

The aim of this article is to discuss practical issues related to current $\mathrm{HCV}$ management and disease elimination in Greece and to provide ideas that may assist clinicians to increase screening and linkage to care in order to achieve 
the HCV elimination goals. It includes opinions expressed during a scientific meeting held in June 2017 in Athens regarding $\mathrm{HCV}$ elimination in Greece, updated to reflect the new situation after the introduction of the Hellenic HCV Action Plan and the unrestricted access to direct acting antivirals (DAAs).

\section{Access to HCV treatment/DAAs}

Universal access of Greek patients to DAA treatment was granted in September 2018. The decision followed a 6-year period of restrictions based on liver-disease severity (Table 2) that excluded a very large proportion of patients (up to $40 \%$ of the general population [8] and 50\% of PWID [12]) with mild disease from access to DAAs.

John Goulis has served as an advisor/lecturer for Bristol-Myers Squibb, Gilead, GlaxoSmithKline, Merck Sharp \& Dohme, Roche, and has received grant support from Bristol-Myers Squibb.

Vana Sypsa has received grant/research support from Gilead and AbbVie, and has served as an advisor/lecturer for: Gilead, AbbVie, and Janssen.

Christos Lionis has received grant support for a collaborative study from Schering-Plough.

George V. Papatheodoridis has received grant/research support from AbbVie, Bristol-Myers Squibb, Gilead, Janssen; has served as an advisor/consultant for AbbVie, Boehringer Ingelheim, BristolMyers Squibb, Gilead, GlaxoSmithKleine, Janssen, Merck Sharp \& Dohme, Novartis, Roche; has delivered sponsored lectures for AbbVie, Bristol-Myers Squibb, Gilead, GlaxoSmithKline, Janssen, Merck Sharp \& Dohme, Novartis, Roche; and was a member of data Safety Management Board for Gilead.

Spilios Manolakopoulos has served as an advisor/lecturer for AbbVie, Bristol-Myers Squibb, Gilead, GlaxoSmithKline, Merck Sharp \& Dohme, Novartis, and Roche and has received grant support from Bristol-Myers Squibb, Gilead, and Regulus.

Ioannis Elefsiniotis has served as an advisor for Gilead, AbbVie and BMS, has delivered sponsored lectures for AbbVie, BMS, MSD, Gilead, has participated in Phase II-III studies for AbbVie and Regulus, and has received grant support from AbbVie.

Olga Anagnostou has served as an advisor/lecturer for Gilead (pro bono).

Christos Tsoulas is an employee of Gilead Sciences Hellas, Greece.

Angelos Hatzakis has received research grants from AbbVie, Gilead, and MSD, unrestricted grants from AbbVie, BMS, Gilead, MSD, and Novartis, has served as an advisor/lecturer for BMS, Gilead, MSD, and AbbVie, and is Co-Chair of the Hepatitis B and C Public Policy Association funded by AbbVie, BMS, Gilead, and MSD.

George N. Dalekos has served as an advisor/lecturer for AbbVie, Bayer, Bristol-Myers Squibb, Gilead, Janssen, Novartis, Roche, and has received grant support from Bristol-Myers Squibb, Gilead, and Roche.

Conflict of Interest: The article includes opinions expressed during a Gilead-sponsored scientific meeting held at the end of June 2017. Data have been updated to reflect the current HCV landscape in Greece. No compensation has been provided to any of the authors for the preparation of this manuscript.
Patients naïve to DAAs can be treated with any of the options included in Table 3, as specified by the Hellenic Association for the Study of the Liver (HASL) and according to product labeling. DAA-experienced patients have access to the triple combination of sofosbuvir/velpatasvir/voxilaprevir, the only treatment option approved in Europe for patients experienced with nonstructural protein $5 \mathrm{~A}$ inhibitors.

Real-life data from DAAs in Greek HCV patients are restricted mainly to patients with advanced disease. These data are extracted from the HERACLIS cohort, the largest national HCV cohort of patients treated with DAAs. Sustained virological response (SVR) and treatment completion rates are high $(>90 \%)$ and confirm the results of the large phase 3 clinical trials. The safety profile was excellent, as indicated by the very low discontinuation rates $[13,14]$.

There are real-life data available for patient populations of special interest. The most important data come from beta-thalassemia major patients with advanced liver disease. Sinakos et al reported a study of 61 thalassemic patients with advanced HCV (80\% cirrhotics) treated with DAAs [15]. Overall SVR rates were $90 \%$. All regimens were well tolerated and no major adverse events or drug interactions were observed. Approximately half of the patients who received ribavirin had increased needs for blood transfusion. Similar results have recently been reported by Zachou et al [16] in 11 patients (10 treatment-experienced) with betathalassemia major and advanced liver disease due to chronic HCV infection (SVR 100\%). The abovementioned data support the Guidelines of the European Association for the Study of the Liver (EASL) and the HASL that patients with hemoglobinopathies can be treated with the same interferon (IFN)a-free regimens, optimally without ribavirin, as the general HCV population.

\section{What is required from Greece to reach WHO goals for HCV elimination?}

To achieve the elimination of viral hepatitis as a public health threat, the WHO has set two specific impact targets for countries: a $65 \%$ reduction in the number of viral hepatitis deaths and a $90 \%$ reduction in the number of new chronic viral infections by 2030 [11]. The first target which concerns mortality, can be achieved though treatment; the second which concerns incidence, is attainable by targeting the population transmitting HCV through prevention measures and adequate treatment. Currently, the transmission of HCV in Greece occurs mainly among PWID. Thus, prevention can be achieved by increasing the provision of harm-reduction services in this population (needle and syringe programs, opioidsubstitution treatment programs). The concept of treatment as prevention also applies: if active PWID receive treatment and are cured, they no longer transmit.

Mathematical models can be employed to assess if $\mathrm{HCV}$ elimination is possible in Greece. These models use country- 
Table 1 Summary findings of HCV prevalence studies in Greece

\begin{tabular}{lccc}
\hline Source & $\begin{array}{c}\text { \% Anti-HCV- } \\
\text { positive }\end{array}$ & $\begin{array}{c}\text { Adult anti-HCV-positive } \\
\text { patients } \\
\text { N (95\%CI) }\end{array}$ & $\begin{array}{c}\mathrm{Chronic} \mathrm{HCV}^{*} \text { patients } \\
\mathrm{N}(95 \% \mathrm{CI})\end{array}$ \\
\hline $\begin{array}{l}\text { Hprolipsis (2013-15) } \\
\text { Greek Health Examination Survey with blood samples } \\
\text { and questionnaires (corrected for high-risk individuals) }\end{array}$ & 1.03 & 92,700 & 74,200 \\
$\begin{array}{l}\text { Telephone Survey (2012) } \\
\text { Age-adjusted for the adult population and corrected } \\
\text { for high-risk individuals (self-reported HCV status) }\end{array}$ & 1.66 & $167,000-104,000)$ \\
\hline
\end{tabular}

Both studies are incorporated in the Hellenic HCV National Plan. ${ }^{*} 80 \%$ of anti-HCV-positive by ELISA have viremia CI, confidence interval; $H C V$, hepatitis $C$ virus

Table 2 Access to direct-acting antiviral agents (DAAs) in Greece according to fibrosis/cirrhosis status

\begin{tabular}{|c|c|c|c|c|c|}
\hline $\begin{array}{l}\text { Access to DAAs } \\
\text { in Greece }\end{array}$ & 2012 & 2014 & 2015 & $\begin{array}{l}\text { July } \\
2017\end{array}$ & $\begin{array}{l}\text { September } \\
2018\end{array}$ \\
\hline $\begin{array}{l}\text { F4 } \\
\text { Treatment } \\
\text { Experienced }\end{array}$ & & & & & \\
\hline $\begin{array}{l}\text { F4 } \\
\text { Treatment- } \\
\text { naïve }\end{array}$ & & & & & \\
\hline $\begin{array}{l}\text { F3 } \\
\text { Treatment- } \\
\text { Experienced }\end{array}$ & & & & & \\
\hline $\begin{array}{l}\text { F3 } \\
\text { Treatment- } \\
\text { naïve }\end{array}$ & & & & & \\
\hline F2 & & & & & \\
\hline F0-1 & & & & & \\
\hline
\end{tabular}

specific data as input and simulate the progression of $\mathrm{HCV}$-infected people through disease stages, using appropriate transition probabilities. In this way, we are able to estimate $\mathrm{HCV}$ incidence and disease burden in the future under various possible strategies of prevention and treatment $[17,18]$.

The goal of reducing HCV mortality in Greece depends on two key parameters: the efficacy of treatment and treatment coverage. Based on the data from the Greek HCV treatment registry, approx. 2000 patients received treatment in 2017 [19]. In order to reach the mortality goal, a possible realization of the treatment strategy would be to increase the annual number of treated patients to 4700 for the years $2017-2019,6800$ for 2020 2023 , and 7000 for 2024-2030 [4,18]. The increase in treatment coverage presupposes a corresponding increase in the number of patients diagnosed per year.

To achieve the goal of $90 \%$ reduction in HCV incidence, a model has been applied to the population of PWID, as this is the only known group with continuing transmission [17]. Based on this model, annual HCV incidence among drug users in Athens would be reduced by $88 \%$ in 2030 if more than 664 PWID received treatment per year, assuming a $2 \%$ annual increase in the coverage of harm reduction programs.

\section{Hellenic HCV National Plan}

As a result of the progress in the treatment of HCV infection and of the Global Health Sector Strategy on viral hepatitis, an updated national plan for hepatitis $C$ was necessary. The Hellenic National Plan for Hepatitis C was officially released and presented by the Minister of Health and the General Secretary for Public Health on July 28, 2017 [4]. It is a detailed manuscript that includes an analysis of the current $\mathrm{HCV}$ landscape, the strategic design, the goals and actions, and eventually the implementation process for HCV elimination.

The strategic design of the plan describes the aim, the values, the priorities, the administration process, the key goals and the anticipated outcomes. The main aim of the plan is to highlight the importance of $\mathrm{HCV}$ as a national public health problem and discuss the significance of prompt diagnosis and surveillance by the appropriate services/ groups for optimal disease management. The long-term aim is to achieve gradual management and control of the HCV infection and eventually its elimination, by 2030, according to the WHO strategic plan [11]. The goals refer 
Table 3 Recommended regimens according to the Hellenic Association for the Study of the Liver for DAA-naive patients

\begin{tabular}{|c|c|c|c|c|}
\hline GT & TN without cirrhosis & TE without cirrhosis & TN with cirrhosis & TE with cirrhosis \\
\hline GT1a & $\begin{array}{l}\mathrm{SOF} / \mathrm{LDV} \times 8 \mathrm{w} \\
\mathrm{PrOD}+\mathrm{RBV} \times 12 \mathrm{w} \\
\mathrm{GZR} / \mathrm{EBR}^{2} \times 12 \mathrm{w} \\
\mathrm{SOF} / \mathrm{VEL} \times 12 \mathrm{w} \\
\mathrm{GLE} / \mathrm{PIB} \times 8 \mathrm{w}\end{array}$ & $\begin{array}{l}\text { SOF/LDV } \times 12 \mathrm{w} \\
\mathrm{PrOD}+\mathrm{RBV} \times 12 \mathrm{w} \\
\mathrm{GZR} / \mathrm{EBR}^{2} \times 12 \mathrm{w} \\
\mathrm{SOF} / \mathrm{VEL} \times 12 \mathrm{w} \\
\mathrm{GLE} / \mathrm{PIB} \times 8 \mathrm{w}\end{array}$ & $\begin{array}{l}\text { SOF/LDV } \times 12 \mathrm{w} \\
\mathrm{PrOD}+\mathrm{RBV} \times 12 \mathrm{w} \\
\mathrm{GZR} / \mathrm{EBR}^{2} \times 12 \mathrm{w} \\
\mathrm{SOF} / \mathrm{VEL} \times 12 \mathrm{w} \\
\mathrm{GLE} / \mathrm{PIB} \times 12 \mathrm{w}\end{array}$ & $\begin{array}{l}\text { SOF/LDV+RBVX12w } \\
\text { PrOD+RBV } \times 12 \mathrm{w} \\
\text { GZR/EBR }{ }^{2} \times 12 \mathrm{w} \\
\text { SOF/VEL } \times 12 \mathrm{w} \\
\text { GLE/PIB } \times 12 \mathrm{w}\end{array}$ \\
\hline GT1b & $\begin{array}{l}\text { SOF } / \text { LDV } \times 8 \mathrm{w} \\
\text { PrOD }{ }^{3} \times 8-12 \mathrm{w} \\
\text { GZR } / \mathrm{EBR}^{3} \times 8-12 \mathrm{w} \\
\text { SOF } / \text { VEL } \times 12 \mathrm{w} \\
\text { GLE } / \mathrm{PIB} \times 8 \mathrm{w}\end{array}$ & $\begin{array}{l}\text { SOF/LDV } \times 12 \mathrm{w} \\
\mathrm{PrOD} \times 12 \mathrm{w} \\
\text { GZR/EBR } \times 12 \mathrm{w} \\
\text { SOF/VEL } \times 12 \mathrm{w} \\
\text { GLE } / \mathrm{PIB} \times 8 \mathrm{w}\end{array}$ & $\begin{array}{l}\text { SOF/LDV } \times 12 \mathrm{w} \\
\text { PrOD } \times 12 \mathrm{w} \\
\text { GZR/EBR } \times 12 \mathrm{w} \\
\text { SOF } / \text { VEL } \times 12 \mathrm{w} \\
\text { GLE } / \mathrm{PIB} \times 12 \mathrm{w}\end{array}$ & $\begin{array}{l}\text { SOF/LDV }+ \text { RBVX } 12 \mathrm{w} \\
\text { PrOD } \times 12 \mathrm{w} \\
\text { GZR/EBR } \times 12 \mathrm{w} \\
\text { SOF/VEL } \times 12 \mathrm{w} \\
\text { GLE/PIB } \times 12 \mathrm{w}\end{array}$ \\
\hline GT2 & $\begin{array}{l}\text { SOF/VEL } \times 12 \mathrm{w} \\
\text { GLE/PIB } \times 8 \mathrm{w}\end{array}$ & $\begin{array}{l}\text { SOF/VEL } \times 12 \mathrm{w} \\
\text { GLE } / \mathrm{PIB} \times 8 \mathrm{w}\end{array}$ & $\begin{array}{l}\text { SOF/VEL } \times 12 \mathrm{w} \\
\text { GLE/PIB } \times 12 \mathrm{w}\end{array}$ & $\begin{array}{l}\text { SOF/VEL } \times 12 \mathrm{w} \\
\text { GLE/PIB } \times 12 \mathrm{w}\end{array}$ \\
\hline GT3 & $\begin{array}{l}\text { SOF/VEL } \times 12 \mathrm{w} \\
\mathrm{GLE} / \mathrm{PIB} \times 8 \mathrm{w}\end{array}$ & $\begin{array}{l}\text { SOF/VEL+RBV } \times 12 \mathrm{w} \\
\mathrm{GLE} / \mathrm{PIB} \times 12 \mathrm{w}\end{array}$ & $\begin{array}{l}\text { SOF/VEL+RBV } \times 12 \mathrm{w} \\
\mathrm{GLE} / \mathrm{PIB} \times 12 \mathrm{w}\end{array}$ & $\begin{array}{l}\text { SOF/VEL+RBV } \times 12 \mathrm{w} \\
\text { GLE/PIB } \times 16 \mathrm{w}\end{array}$ \\
\hline GT4 & $\begin{array}{l}\text { SOF/LDV } \times 12 \mathrm{w} \\
\mathrm{PrO}+\mathrm{RBV} \times 12 \mathrm{w} \\
\text { GZR/EBR } \times 12 \mathrm{w} \\
\text { SOF/VEL } \times 12 \mathrm{w} \\
\text { GLE } / \mathrm{PIB} \times 8 \mathrm{w}\end{array}$ & $\begin{array}{l}\text { SOF/LDV+RBVX12w } \\
\text { PrO+RBV } \times 12 \mathrm{w} \\
\text { GZR/EBR } \times 12 \mathrm{w} \\
\text { SOF/VEL } \times 12 \mathrm{w} \\
\text { GLE } / \mathrm{PIB} \times 8 \mathrm{w}\end{array}$ & $\begin{array}{l}\text { SOF/LDV } \times 12 \mathrm{w} \\
\mathrm{PrO}+\mathrm{RBV} \times 12 \mathrm{w} \\
\text { GZR/EBR } \times 12 \mathrm{w} \\
\text { SOF/VEL } \times 12 \mathrm{w} \\
\text { GLE } / \mathrm{PIB} \times 12 \mathrm{w}\end{array}$ & $\begin{array}{l}\text { SOF/LDV+RBVX12w } \\
\text { PrO+RBV } \times 12 \mathrm{w} \\
\text { GZR/EBR } \times 12 \mathrm{w} \\
\text { SOF/VEL } \times 12 \mathrm{w} \\
\text { GLE/PIB } \times 12 \mathrm{w}\end{array}$ \\
\hline
\end{tabular}

${ }^{1}$ Not in GT1a cirrhotic patients with previous null response; ${ }^{2}$ Not in GT1a and HCV RNA $\geq 800,000 \mathrm{IU} / \mathrm{mL} ;{ }^{3} 8 \mathrm{w}$ for F0-F2 and $12 \mathrm{w}$ for F3; ${ }^{4} \mathrm{Not}$ in TE-GT4 (with or without cirrhosis) and HCV RNA $\geq 800,000 \mathrm{IU} / \mathrm{mL}$

RBV free options are preferred. Patients with renal insufficiency, estimated glomerular filtration rate (eGFR) $<30 \mathrm{~mL} / \mathrm{min}$, should be treated with PrOD, GZR/EBR or GLE/PIB. Patients with decompensated disease should be treated with SOF/LDV+RBV or SOF/VEL+RBV for $12 \mathrm{w}$.

$D A A$, direct-acting antiviral agents; GT, genotype; GLE/PIB, glecaprevir/pibrentasvir; GZR/EBR, grazoprevir/elbasvir; $H C V$, hepatitis $C$ virus; $\operatorname{PrO}( \pm D)$,

paritaprevir/ritonavir/ombitasvir( \pm dasabuvir); RBV, ribavirin; SOF, sofosbuvir; SOF/LDV, sofosbuvir/ledipasvir; SOF/VEL, sofosbuvir/velpatasvir; TN, treatmentnaive; TE, treatment-experienced

to the development of the appropriate social environment, the organization of holistic and integrated healthcare services, the organization of international cooperation, and the development of mechanisms for data collection and registries as a basis for evidence-based health policy interventions. The anticipated outcomes include a gradual decline in the existing cases and the burden of disease in morbidity and mortality through giving patients equal access to appropriate treatment. Additional outcomes focus on the decline of viral transmission through healthy behaviors and public awareness, and programs of prevention and treatment, particularly in high-risk groups. The elimination of HCV as a major threat to public health by the year 2030, in agreement with the WHO strategic plan, can be gradually accomplished by achieving these outcomes.

The need for reorganization of structures and health care services is documented, while there are 4 policy areas and related actions for the implementation and development of the plan. The first area focuses on prevention and public awareness, and includes specific actions for awareness and prevention in high-risk groups and in the general population, with emphasis on young people and on the continuing education of medical and paramedical personnel. The second arm is related to asymptomatic screening and includes 2 main programs: one for the general population and one for high-risk groups (Table 4). The target of screening programs is to increase the proportion of diagnosed patients from $19 \%$ in 2012 to $40 \%$ in 2020 and $90 \%$ in 2030 . The main activity for general population screening is the introduction of a birth-cohort screening recommendation for individuals born in Greece between 1945 and 1980, as more than 3 of 4 patients living with HCV in Greece were born during this period $[4,20]$. The third arm is related to diagnosis and treatment and includes two main actions: one to establish diagnostic protocols for asymptomatic screening at primary care health services, and one to ensure that HCV patients have access to appropriate treatment. Finally, the fourth arm refers to the patients' follow up and chronic care.

The implementation of the HCV National Plan has started and a Committee following its implementation has been in place since January 2018. Prompt implementation of most of the actions of the Hellenic National Plan to improve diagnosis and optimize patient access to care is required in order to achieve the targets required for HCV elimination [4]. Thus, the Hellenic National Action Plan is a key tool for effective health policy and optimized use of resources in the effort for national HCV elimination.

\section{What is the role of primary health care in HCV elimination?}

There is a growing international interest in the involvement of general practitioners (GPs) and primary care practitioners (PCPs) in the early diagnosis and management of $\mathrm{HCV}$ infection. 
Table 4 HCV screening recommendations included in the HCV Hellenic National Plan

\begin{tabular}{|c|c|}
\hline Target population & HCV screening recommendations \\
\hline General & $\begin{array}{l}\text { Birth cohort screening: Adults born from } \\
1945 \text { to } 1980\end{array}$ \\
\hline \multirow[t]{12}{*}{ High-risk groups } & - Persons with elevated transaminases \\
\hline & $\begin{array}{l}\text { - People who inject drugs (current and former } \\
\text { IV drug users) }\end{array}$ \\
\hline & $\begin{array}{l}\text { Recipients of a transfusion of blood, blood } \\
\text { components, or an organ transplant before } \\
1992\end{array}$ \\
\hline & $\begin{array}{l}\text { - Persons who are receiving or have received } \\
\text { hemodialysis }\end{array}$ \\
\hline & $\begin{array}{l}\text { - Persons who have been parenterally exposed } \\
\text { to potentially HCV infected medical } \\
\text { instruments or paramedical procedures }\end{array}$ \\
\hline & $\begin{array}{l}\text { - Long-term steady sex partners of } \\
\text { HCV-positive persons }\end{array}$ \\
\hline & $\begin{array}{l}\text { - Persons with a history of multiple sex } \\
\text { partners }\end{array}$ \\
\hline & - Children born to HCV-positive women \\
\hline & - Persons with HIV infection \\
\hline & - Persons with HBV infection \\
\hline & - Incarcerated persons \\
\hline & $\begin{array}{l}\text { - Immigrants from high HCV prevalence } \\
\text { countries }\end{array}$ \\
\hline
\end{tabular}

One pioneer study published in the Australian Family Physician (1999), reported on Greek GPs management of $\mathrm{HCV}$-infected patients in a period when the IFNa-2b injectionbased therapy was used [21]. General practice in Greece has also contributed to the identification of hidden transmission routes [22] and the assessment of the high burden of HCV infection in rural Greece $[23,24]$. However, there are many questions regarding the role of GPs and other PCPs in HCV management, especially in a period when effective treatment is available. The question seems to be especially relevant in countries like Greece, where primary care needs to address quality improvement and an integrated primary care system is still lacking [25]. There are also certain unanswered questions which primary care may play an important part in answering.

These are summarized as follows:

- What is the prevalence of HCV infection in primary care practice settings?

- What is the probability of anti-HCV seropositivity according to patient characteristics?

- What are the compliance and adherence rates of seropositive patients to HCV treatment in primary care practice settings?

- What is the natural course of HCV infections among patients diagnosed in the primary care setting and what comorbidities do they have?

Based on local and international experience, the contribution of PCPs to the management of HCV infection needs to be further explored with a focus on the following areas:

- Educating patients on the importance of early diagnosis and treatment.
- Screening of adults born from 1945-1980, according to the Hellenic HCV National Plan.

- Identification of high-risk individuals, as well as those who have received previous treatment modalities, and inviting them for screening.

- Testing anti-HCV-positive patients with a reliable molecular test (HCV-RNA), preferably using the same blood sample. Patients with anti-HCV ELISA positive test are often lost to follow up for HCV-RNA determination.

- Participation of PCPs in the full laboratory testing of seropositive patients and disease staging, as well as in treatment decisions (jointly with hepatologists).

- PCP participation in HCV patient monitoring and reporting with regard to $\mathrm{HCV}$ management.

- Active PCP involvement in the management of comorbidities associated with the HCV infection.

To what extent are PCPs trained to take on the above responsibilities? There are empirical data showing that intensive training may increase the proportion of PCPs who successfully manage these responsibilities [26]. To that end, a training module that will be provided to PCPs in a pilot setting that includes communication and motivational skills, as well as clinical skills related to the effective management of $\mathrm{HCV}$ infection, seems to be essential. Trained PCPs can significantly support HCV elimination by screening of asymptomatic individuals, by being the first contact high-risk patients have with integrated and coordinated services, by educating patients to ensure their engagement in HCV treatment, and by effectively collaborating with the other healthcare stakeholders, including community nurses and pharmacists, for optimal patient management.

\section{Diagnosed HCV patients lost to follow up: What can we do to bring diagnosed HCV patients back to care?}

Patients diagnosed with $\mathrm{HCV}$ infection often do not receive antiviral treatment [27]. There are several reasons that keep HCV patients away from medical care $[27,28]$. These include the asymptomatic nature of $\mathrm{HCV}$ infection, a lack of awareness regarding the long-term complications of $\mathrm{HCV}$, and the high frequency of psychiatric comorbidities combined with social stigma and discrimination. In addition, a previous negative experience due to IFN-related side effects in association with a poor knowledge of the favorable therapeutic profile of the new DAAs, financial difficulties, and poor trust in the healthcare system are often cited by PWID as important reasons why they do not take HCV medication [29].

There is evidence from tertiary liver centers in Greece suggesting that almost half of the HCV patients who visit an outpatient liver clinic are lost to follow up or remain untreated [30,31]. Data from tertiary hepatology centers from the IFNa era have shown that a large number of patients $(>40 \%)$ were either lost to follow up during the initial evaluation process, before treatment initiation with IFN-based regimens, or refused antiviral therapy. The other category of patients lost to follow up was those who had not achieved SVR [30]. 
Local studies have revealed some common characteristics among patients lost to follow up. These include the absence of diagnostic tests, such as liver biopsy or transient elastography and normal transaminase levels (lack of urgency) [30]. Patients are typically young, treatment-naïve, without cirrhosis, and either have a history of IV drug use or are currently using (Elefsiniotis et al, unpublished observations). For PWID in particular, distinct epidemiological and liver disease features may play a role, as they tend to be younger, with less severe liver disease compared to non-PWID [32].

In the era of unrestricted access to DAAs, actions that link HCV-infected patients back to medical care are urgently required. Information, awareness and motivation for the "new age" of HCV therapy (high cure rates and favorable safety profile) provided by media, social networking and other social sources are of great importance. Close collaboration between addiction and hepatology centers is necessary to bring infected PWID back to care. Medical units should be supported by health-record administrative staff, to monitor the epidemiological characteristics and outcomes of therapy, and organize the communication and linkage of "lost" HCV patients with liver units. Educational interventions targeting medical and non-medical hospital staff could help healthcare providers to improve patients' understanding of their disease and their acceptance of treatment. Last but not least, the benefits of HCV eradication should be spread within the PWID community, especially by those patients who successfully commenced treatment (i.e., a "bring a friend" campaign).

\section{HCV in PWID}

In Greece, as in many Western countries, drug users, especially those with injecting or/and sharing history, represent the main risk group for $\mathrm{HCV}$ infection acquisition $[6,7,33]$. The actual HCV incidence among PWID is unknown in Greece because of the lack of systematic testing and surveillance [34].

According to a recent report from the Greek Monitoring Centre for Drugs (EKTEPN), anti-HCV seroprevalence among PWIDs is almost $62.0 \%$ nationally [35]. A duration of injecting history longer than 2 years and a history of previous therapeutic attempts are associated with a higher HCV prevalence. The highest prevalence $(69.6 \%)$ is observed in heroin users under opioid substitution treatment (OST), with residents of Athens presenting a much higher prevalence compared to the rest of Greece (85.6\% vs. $64.6 \%$, respectively). Despite small longitudinal changes, the national prevalence of anti-HCV seropositivity has remained stable during the last 6 years, after the significant increase observed in 2010 that coincided with the HIV epidemic onset among drug users in the Athens Metropolitan Area. Fibrosis staging by the determination of liver stiffness measurement using the transient elastography method in 827 anti-HCV-PWIDs under OST revealed that $16.0 \%$ of patients had cirrhosis $(>12 \mathrm{kPa})$, while $10 \%, 18 \%$ and $56 \%$ were classified in stages F3, F2 and F0-1, respectively [36].

The number of high-risk heroin users (age 15-64 years) is estimated by EKTEPN to be as high as 16,701 persons
(95\% confidence interval [CI] 14,346-19,677) using the capture-recapture method. The number represents a rate of $2.38 \%$ o (95\%CI 2.05-2.81) of the general population [35]. In 2015 approximately 10,000 PWID received methadone or buprenorphine at OKANA treatment centers (OKANA: Organization against Drugs, is a public sector organization; the only one in Greece authorized to provide OST). During the same period, an additional number of approximately 2300 persons were treated at therapeutic communities.

Poor acceptance of IFN-a by drug users and considerations regarding reinfection along with poor adherence were the main treatment barriers during the IFN era. Several efforts are required to overcome these barriers. In our personal experience, the initiative that remains most effective and stable over time is the combined multidisciplinary efforts of medical doctors working in the addiction field and hepatologists, with the support of addiction treatment staff (social workers, psychologists and nurses). SVR and adherence rates are comparable with those of non-PWID HCV patients at the same hepatology centers [37-39].

As expected, DAAs offer improvements over IFN-a in terms of treatment convenience and effectiveness, as is well accepted by both doctors and patients organizations; however, it is not yet clear if these advantages reach the majority of drug addicts in Greece. Even if we overlook the drug users' information gap, previous bad experiences continue to erode the confidence of PWID in health personnel and the health system. Pretreatment diagnostics procedures (GT and transient elastography), often provided in different but equally inhospitable environments, are still not covered by social insurance and represent significant barriers that impede access to care. Nevertheless, PWID under OST have shown very good real-life results with DAA treatment under the above mentioned multidisciplinary team approach [35], although numbers are far below those required for $\mathrm{HCV}$ elimination according to the Hellenic $\mathrm{HCV}$ National Plan $[4,17]$.

\section{Proposed actions to optimize care of PWID infected with HCV}

To serve both patients' rights to get treatment and WHO targets for $\mathrm{HCV}$ elimination, a new individualized service model needs to be applied to PWID: a model that takes into account the special characteristics of the population (social marginalization, lack of trust in health services, chaotic lifestyle features, lack of information, and low HCV awareness) and the unquestionable advantages of the new therapies (high efficacy, short duration, lack of toxicities).

Almost half of PWID with HCV are not aware of their infection. The awareness activities that can improve services for PWID are those that educate them explicitly and repeatedly about safer injection practices and about the availability of the current HCV treatment options. Education and counseling in non-infected individuals may modify high-risk behaviors and lead to the adoption of 
risk reduction measures [40]. PWID who are aware of their infection are more prone to request counseling about risk factors for infection, reinfection, and transmission to others, which may potentially limit the HCV spread among IV drug users.

Active search for new HCV cases should be implemented intensively in order to serve the HCV elimination target. Despite the fact that HCV testing uptake is high, at least among PWID entering OST in Greece, there is still a need for scaling up screening, especially for those younger than 25 years who are at the beginning of their hazardous use [34]. Regular retesting opportunities for seronegative PWID and treatment responders should be included in a plan that aims to address the issue holistically. The implementation of the abovementioned measures can significantly improve HCV diagnosis and treatment coverage among PWID.

Optimal interventions should integrate $\mathrm{HCV}$ testing and treatment within community addiction centers [41]. It seems reasonable that, by offering all the pretreatment procedures under the same "roof", we can increase the treatment opportunities for drug addicts. One-stop clinics, offering integrated care in a patient-friendly environment (i.e., within the framework of an addiction treatment center), are essential to complete all the pretreatment diagnostic procedures without additional needs for travelling and/or appointments. These units should include a multidisciplinary team of addiction specialists, hepatologists, nurses, and administrative staff, and should be equipped with all the necessities (at least transient elastography, HCV viral load/genotyping). In addition, these units could organize rotations in rural areas for PWID living away from cities.

Active drug users, a subgroup with restricted access to treatment, can be reached by adding a mobile unit within the framework of the one-stop clinic. By "mobilizing” our one-stop facilities we can reach these patients at their gathering places (hot-spots), instead of asking them to visit healthcare facilities with rigid rules and fixed schedules.

\section{Concluding remarks}

Greece has made significant positive steps towards $\mathrm{HCV}$ elimination over the recent years. The HCV Hellenic National Plan seems to be a valuable tool to serve as a roadmap for disease elimination by 2030 , according to the WHO strategy. The major challenge is the implementation of the Hellenic National Plan regarding the diagnosis, linkage-to-care and treatment of HCV patients.

The hepatological community can lead the HCV elimination cause and support actions to efficiently increase the number of HCV patients diagnosed and treated in Greece. A proactive approach to reach out to patients, physicians from other specialties and other stakeholders is required in an attempt to achieve the goals of the HCV Hellenic National Plan. Some examples of activities that hepatologists can undertake in their local practice to support $\mathrm{HCV}$ elimination are summarized in Table 5.

Partnerships of hepatologists with GPs and PCPs seem to be of the utmost importance for the promotion of asymptomatic screening in the general population among individuals born between 1945 and 1980, thus enabling obscure HCV patients to be diagnosed. Experience with these programs can serve as a pilot to identify issues regarding HCV treatment in other settings and will produce positive messages to support the ultimate cause, $\mathrm{HCV}$ elimination.

Table 5 Examples of actions by hepatologists for the implementation of the HCV National Plan

\begin{tabular}{l} 
Screen patients in hospitals according to the HCV Hellenic National Plan recommendations. Close collaboration with hospital lab and other \\
clinics for a referral network to ensure linkage to care \\
Identification of all HCV patients in Hepatology Clinic archives who are lost to follow up. Recall patients by personal communication \\
Register all HCV patients in the national HCV registry, regardless of the decision to treat \\
Reinforce the capacity of the Hepatology Centers. Ensure dedicated medical, nursing and administrative support \\
Identify local barriers to care (e.g., lack of availability of transient elastography/HCV RNA quantification, genotype determination) and explore \\
solutions \\
Increase awareness of lay people in the local community via media, social networks, collaboration with local authorities and the local Hellenic \\
Association for the Study of the Liver \\
"Coalition of the willing". Create a network of sensitized physicians and educate them to refer their patients. Educate physicians of other \\
specialties, pharmacists and non-medical personnel in hospitals and in primary and secondary care about the utmost importance of \\
asymptomatic screening \\
Collaborate with other stakeholders to identify, screen and treat groups of special interest with a disproportionally high incidence of chronic \\
hepatitis C, e.g., PWID, incarcerated, beta-thalassemia patients, hemodialysis patients, immigrants and refugees, etc. \\
Visit addiction facilities in collaboration with addiction specialists (e.g., substitution programs) outside the non-friendly hospital environment. \\
Test and treat active drug users, where feasible \\
Explore and take advantage of HCV networks. "Bring a friend", peer-to-peer approach. \\
Generate "micro-elimination" examples. \\
Advocate for awareness and screening campaigns \\
\hline$H C V$, hepatitis C virus
\end{tabular}


An important action that can be undertaken by hepatologists to show that HCV elimination is feasible is the generation of "micro-elimination" examples [42]. The term refers to proofof-concept interventions showcasing disease elimination in specific geographic or special group settings [42]. Hepatologists can partner with physicians who treat special groups to systematically screen, treat and eliminate $\mathrm{HCV}$ in these settings. Examples may include HCV elimination in addiction centers, prisons, thalassemia/bleeding disorder units, renal units, and special HIV infectious disease clinics.

In conclusion, the presence of a thorough HCV National Plan and unrestricted access to DAAs are necessary but not sufficient tools for HCV elimination. A significant increase in $\mathrm{HCV}$ screening in the general population, and the adoption of best practices for screening and linkage to care in groups of special interest (e.g., PWID, incarcerated patients, immigrants) are important steps towards achieving the ambitious objectives of the National Plan. In this context, the active participation of the hepatological community, along with practitioners in primary and secondary care, as well as those involved in integrated care units, is critical for the successful implementation of the Hellenic National Plan and the elimination of $\mathrm{HCV}$ in Greece.

\section{References}

1. Papatheodoridis G, Sypsa V, Kantzanou M, Nikolakopoulos I, Hatzakis A. Estimating the treatment cascade of chronic hepatitis B and C in Greece using a telephone survey. J Viral Hepat 2015;22:409-415.

2. Touloumi G, Karakosta A, Kaskafetou S, et al. Treatment cascade of hepatitis B and C in general, migrant and Roma populations. $J$ Hepatol 2017;66(Suppl):S71-S72.

3. Saraswat V, Norris S, de Knegt RJ, et al. Historical epidemiology of hepatitis C virus (HCV) in select countries - volume 2. J Viral Hepat 2015;22(Suppl 1):6-25.

4. Hellenic National Plan for Hepatitis C, 2017. [ebook] Athens, Greece: Hellenic Ministry of Health. Available at: http://www. moh.gov.gr/articles/ministry/grafeio-typoy/press-releases/4865ethniko-sxedio-drashs-gia-thn-antimetwpish-ths-hpatitidas-c [Accessed March 26, 2019] [Greek].

5. Raptopoulou M, Tzourmakliotis D, Nikolopoulou N, et al. Epidemiology of hepatitis $C$ in Greece: Results of the nationwide HEPNET GREECE cohort study. 41 $1^{\text {st }}$ EASL. Austria, 2006. Hepatology 2006;44(Suppl 2):S203-S204.

6. Gatselis NK, Rigopoulou E, Stefos A, Kardasi M, Dalekos GN. Risk factors associated with HCV infection in semi-rural areas of central Greece. Eur J Intern Med 2007;18:48-55.

7. Raptopoulou M, Touloumi G, Tzourmakliotis D, et al. Significant epidemiological changes in chronic hepatitis $\mathrm{C}$ infection: results of the nationwide HEPNET-GREECE cohort study. Hippokratia 2011;15:26-31.

8. Papatheodoridi M, Dalekos GN, Goulis J, et al. Prioritization for interferon-free regimens and potential drug interactions of current direct-acting anti-hepatitis $\mathrm{C}$ agents in routine clinical practice. Ann Gastroenterol 2017;30:542-549.

9. Triantos C, Konstantakis C, Tselekouni P, Kalafateli M, Aggeletopoulou I, Manolakopoulos S. Epidemiology of hepatitis C in Greece. World J Gastroenterol 2016;22:8094-8102.

10. Rigopoulou EI, Stefanidis I, Liaskos C, et al. HCV RNA qualitative assay based on transcription-mediated amplification improves the detection of hepatitis $\mathrm{C}$ virus infection in patients on hemodialysis: Results from five hemodialysis units in central Greece. J Clin Virol 2005;34:81-85.

11. WHO (2016). Global health sector strategy on viral hepatitis, 2016-2021. Available at: http://apps.who.int/iris/ bitstream/10665/246177/1/WHO-HIV-2016.06-eng.pdf?ua=1 [Accessed March 26, 2019].

12. Kranidioti H, Manolakopoulos S, Hatzievagelinou C, et al. Clinical and epidemiologic characteristics of people who inject drugs with chronic hepatitis $\mathrm{C}$ and assessment of access to new antivirals. $13^{\text {th }}$ Congress on Management, Economics and Health Policy, Department of Health Economics, National School of Public Health, Athens- Greece, 12-14 December 2017.

13. Papatheodoridis G, Koskinas J, Goulis J, et al. Changes in the use of direct acting antiviral(s) (DAA) in the treatment of chronic hepatitis C (CHC) patients in clinical practice. HERACLIS: a Hellenic multicenter real-life cohort clinical study. Hepatology 2017;66(Suppl1):603A-604A.

14. Manolakopoulos S, Sevastianos V, Triantafyllou K, et al. Sofosbuvir/ Velpatasvir (SOF/VEL) \pm Ribavirin $(\mathrm{R})$ in the treatment of genotype 3 (GT3) chronic hepatitis C (CHC) patients. HERACLIS: a Hellenic multicenter real-life cohort clinical study. Hepatology 2018;68(Suppl1):378A-379A.

15. Sinakos E, Kountouras D, Koskinas J, et al. Treatment of chronic hepatitis $\mathrm{C}$ with direct-acting antivirals in patients with $\beta$-thalassaemia major and advanced liver disease. Br J Haematol 2017;178:130-136.

16. Zachou K, Arvaniti P, Gatselis NK, et al. Patients with haemoglobinopathies and chronic hepatitis C: A real difficult to treat population in 2016? Mediterr J Hematol Infect Dis 2017;9:e2017003.

17. Gountas I, Sypsa V, Anagnostou O, et al. Treatment and primary prevention in people who inject drugs for chronic hepatitis C infection: Is elimination possible in a high prevalence setting? Addiction 2017;112:1290-1299.

18. Gountas I, Sypsa V, Papatheodoridis G, Souliotis G, Razavi H, Hatzakis A. Is elimination of HCV possible in a country with low diagnostic rate and moderate HCV prevalence?: The case of Greece. J Gastroenterol Hepatol 2017;32:466-472.

19. Kani H. National Plan for Hepatitis C: Barriers and challenges for HCV elimination. Presented at $13^{\text {th }}$ Congress on Management, Economics and Health Policy; 2017; Athens, Greece.

20. Gane E, Kershenobich D, Seguin-Devaux C, et al. Strategies to manage hepatitis $\mathrm{C}$ virus (HCV) infection disease burden - volume 2. J Viral Hepat 2015;22(Suppl 1):46-73.

21. Lionis C, Frangoulis E, Skliros S, Alexandrakis E, Kouroumalis E. How Greek GPs manage hepatitis $C$ infected patients: experiences gained from a primary health care district in rural Crete. Aust Fam Physician 1999;28:207.

22. Lionis C, Vlachonikolis IG, Skliros S, Symeonidis A, Merkouris BP, Kouroumalis E. Do undefined sources of hepatitis $\mathrm{C}$ transmission exist? The Greek study in General Practice. J Viral Hepat 2000;7:218-224.

23. Lionis C, Koulentaki M, Biziagos E, Kouroumalis E. Current prevalence of hepatitis A, B and C in a well-defined area in rural Crete, Greece. J Viral Hepat 1997;4:55-61.

24. Drositis I, Bertsias A, Lionis C, Kouroumalis E. Epidemiology and molecular analysis of hepatitis A, B and C in a semi-urban and rural area of Crete. Eur J Intern Med 2013;24:839-845.

25. Tsiachristas A, Lionis C, Yfantopoulos J. Bridging knowledge to develop an action plan for integrated care for chronic diseases in Greece. Int J Integr Care 2015;15:e040.

26. Rattay T, Dumont IP, Heinzow HS, Hutton DW. Costeffectiveness of access expansion to treatment of Hepatitis C 
virus infection through primary care providers. Gastroenterology 2017; 153:1531-1543.

27. Papatheodoridis GV, Tsochatzis E, Hardtke S, Wedemeyer H. Barriers to care and treatment for patients with chronic viral hepatitis in Europe: a systematic review. Liver Int 2014;34:1452-1463.

28. Souliotis K, Agapidaki E, Papageorgiou M, Voudouri N, Contiades X. Access to treatment for Hepatitis $\mathrm{C}$ among injection drug users: results from the cross-sectional HOPE IV study. Int $J$ Equity Health 2017;16:101.

29. Dillon JF, Lazarus JV, Razavi HA. Urgent action to fight hepatitis C in people who inject drugs in Europe. Hepatol Med Policy 2016;1:2.

30. Papadopoulos N, Manolakopoulos S, Deutsch M, et al. Frequency and predictors of no treatment in anti-hepatitis $\mathrm{C}$ virus-positive patients at tertiary liver centers in Greece. Eur J Gastroenterol Hepatol 2013;25:587-593.

31. Papastergiou V, Anagnostou O, Deutsch M, et al. Incidence and predictors of hepatitis $\mathrm{C}$ treatment initiation among people who inject drugs: longitudinal data from a Greek tertiary center: 20092015. United European Gastroenterol J 2016;2(Suppl 1).

32. Papastergiou V, Deutsch M, Anagnostou O, et al. Severity and correlates of liver fibrosis assessed by elastography are different between hepatitis $\mathrm{C}$-infected people who inject drugs and patients infected by other routes. Hepatology 2017;66(Suppl 1).

33. Dalekos GN, Manoussakis MN, Zervou E, Tsianos EV, Moutsopoulos HM. Immunologic and viral markers in the circulation of anti-HIV negative heroin addicts. Eur J Clin Invest 1993;23:219-225.

34. Anagnostou O, Fotiou A, Kanavou E, et al; Drug Related Infectious Diseases (DRID) Medical Doctors Group of OKANA. Factors associated with HCV test uptake in heroin users entering substitution treatment in Greece. HIV Med 2018;19(Suppl 1): 34-39.
35. EKTEPN Greek documentation and monitoring centre for drugs, Greek Reitox Focal Point. 2017 Annual report [in Greek]. Available at: http://ektepn.gr/. [Accessed March 26, 2019].

36. Anagnostou O, Kalamitsis G, Tsirogianni E, et al. Overcoming barriers to $\mathrm{CHC}$ treatment: A meaningful and effective collaboration of a public sector organization with a patients' community organization. $6^{\text {th }}$ international Symposium on Hepatitis Care in Substance Users. Jersey City/New York, USA 6-8 September 2017.

37. Manolakopoulos S, Deutsch MJ, Anagnostou O, et al. Substitution treatment or active intravenous drug use should not be contraindications for antiviral treatment in drug users with chronic hepatitis C. Liver Int 2010;30:1454-1460.

38. Anagnostou O. Incidence and predictors of Hepatitis C treatment initiation among people who inject drugs: longitudinal data from a Greek Tertiary Center, 2009-2015. $5^{\text {th }}$ international Symposium on Hepatitis Care in Substance Users. Oslo, Norway 7-9 September 2016.

39. Kranidioti H, Goulis J, Anagnostou O, et al. Direct-acting antiviral therapy in patients with advanced disease: comparison of SVR rates between people who inject drugs (PWID) and non-PWID. $6^{\text {th }}$ international Symposium on Hepatitis Care in Substance Users. Jersey City/New York, USA 6-8 September 2017.

40. Cox J, Morissette C, De P, et al. Access to sterile injecting equipment is more important than awareness of HCV status for injection risk behaviors among drug users. Subst Use Misuse 2009;44:548-568.

41. Korthuis PT, Feaster DJ, Gomez ZL, et al. Injection behaviors among injection drug users in treatment: the role of hepatitis $C$ awareness. Addict Behav 2012;37:552-555.

42. Lazarus JV, Wiktor S, Colombo M, Thursz M; EASL International Liver Foundation. Micro-elimination - A path to global elimination of hepatitis C. J Hepatol 2017;67:665-666. 